\section{CONSECUENCIAS POLÍTICAS DE UNA DISOLUCIÓN DEL ROMANTICISMO (Viena y S. Zweig en los comienzos del siglo $\mathrm{XX}$ )}

\section{Ilia Galán}

Profesor Titular de Estética en la Universidad Carlos III de Madrid Universidad Carlos III, Humanidades, C/ Madrid 126, 28903 Getafe

(Madrid)

ilia.galan@uc3m.es

\section{POLITICAL CONSEQUENCES OF A DISSOLUTION OF THE ROMANTICISM \\ (Viena and S. Zweig by the beginning of the $20^{\text {th }}$ centuryl}

\begin{abstract}
The surprise of S. Zweig when the new barbarians (the Nazis) get the power can be very suggestive for our present. He could not understand that in the learned Germanic lands could make be born that germ against-culture and so atrocious. An analysis of the culture of their time in Vienna, of the writings of Zweig and of that society and the politics of that moment, can clarify the key: Zweig lived in an ivory tower, unaware to the workers suburbs. The vision of the world from the comfort can be corrupted to imagine that the world maybe is crashed. The view of Zweig was too elitist: insufficient, for that reason it could not be explained to it. Yesterday's world collapsed before their eyes. A study of the relationship among the plastic arts, the philosophy, the society and the politics of the time helps to understand why many intellectuals they didn't understand.
\end{abstract}

KEY WORDS: Zweig; nazism; culture; literature; elitism; sociology; collapse.

Si el mundo estético romántico y su versión política más eminente (revolucionaria) se fundamenta en la idea de lo sublime, la evolución del final del siglo XIX y su entrada en el siglo XX, hasta la Primera Guerra Mundial, diluyó sus fundamentos, anclados a su vez en la unitaria idea de totalidad e infinitud, pero manteniendo en buena parte la iconografía o los tratamientos simbólicos y sus temas, aunque sin su fuerza primigenia, como motivos bellos, como adornos o sentimentalismo superfluo, efímero a menudo. Belleza de algo que, en su génesis, fue entendido como ruptura y trágica realidad, difícil de interpretar como belleza plácida o armónica; tales son las pinturas negras de Goya o la quinta sinfonía de Beethoven, la música de Wagner o la literatura de Hölderlin, e incluso los paisajes de C. D. Friedrich, como el Monje a la orilla del mar, que tienen no poco de inquietante y evidentes pretensiones transcendentales.
RESUMEN: La sorpresa de Zweig cuando los nuevos bárbaros (los nazis) llegan al poder puede ser muy esclarecedora para nuestro presente. Él no podía entender que las cultísimas tierras germánicas pudieran hacer nacer ese germen anticultural y atroz. Un análisis de la cultura de su época en Viena, de los escritos de Zweig y de la sociedad y la política de ese momento desvelan la clave: Zweig vivía en una torre de marfil, ajeno a los barrios obreros. La visión del mundo desde la comodidad puede estar viciada por imaginarse que el mundo es equilibrado. La mirada de Zweig era demasiado elitista: insuficiente, por eso no pudo explicárselo. El mundo de ayer se derrumbó ante sus ojos. Un estudio de la relación entre las artes plásticas, la filosofía, la sociedad y la política de la época ayuda a entender por qué muchos intelectuales no entendieron.

PALABRAS CLAVE: Zweig; nazismo; cultura; literatura; elitismo; sociología; colapso.

La Viena que corresponde al período de Stefan Zweig está anclada en un pasado extremadamente brillante, y de este inmediato pasado y todavía fecundo presente, Zweig toma casi sólo lo que le resulta amable y adecuado, no distorsionante, en plena consonancia con el espiritu burgués de comodidad, de un poder que se creía casi perfecto y eterno. Por ello no podía admitir, en cuanto a esplendor logrado, ninguna distorsión siquiera en lo estético; ninguna rebelión o camino alternativo al que tan "buenos" resultados había proporcionado hasta entonces; desde un serio absolutismo que pobló el Imperio de espías y delaciones, como sucedió en la época de Beethoven y que explica el esplendor musical del momento frente al vacío filosófico o literario de aquellos años, hacia una lenta y difícil evolución en busca de moldes más liberales. En el final del siglo XIX y el principio del XX, Viena parece un 
mundo absolutamente estable, como si el modelo, para los burgueses, hubiera llegado casi a su perfección, con una aristocracia plegada en parte a su pujanza. Muchos burgueses accedian a puestos fundamentales de decisión para el Imperio, mayormente por sus méritos y ya no sólo por nacimiento. El afán por calcular rentas futuras o el ansia de poder llegar a ser funcionario imperial resumía las más altas aspiraciones de muchos.

Sin embargo, esa altiva corte vienesa, de pulcritud externa evidente en su arquitectura oficial, en avenidas y palacios, escondía o no quería ver, tapándolas, fallas estructurales graves. El pluralismo de naciones, lenguas o religiones que albergaba dentro de sus fronteras no era fácil, sino al contrario, tal y como se vio en el desencadenamiento de la Primera Guerra Mundial. La disolución posterior del hacía poco esplendoroso Imperio, unida al sabor de la derrota, y su derrumbe y entrega al fascismo que la engulló bajo las botas dirigidas desde Berlín, como provincia, fue para muchos una pesadilla imposible que les anonadó, y entre ellos Zweig, como si no dieran crédito a lo que veian. Ese Imperio, culturalmente diverso, resultaba más que paradójico en no pocos aspectos, y así hallamos que las figuras más destacadas de la literatura checa (Kafka y Rilke) escribian en alemán, vehículo idiomático unificador en un estado fragmentado por demasiadas lenguas, lo mismo que, por otra parte, también era la lengua materna y habitual de muchos nacionalistas eminentes, como Dvorak. Por otro lado, la historia y la cultura húngara parecía desarrollarse al margen de la capital vienesa, en una especie de paridad capitalina que, sin embargo, no terminaba de igualar a Budapest con la preeminencia de Viena. Los escritores húngaros, siguiendo la estela romántica de Petöfi, Mór Jókai o Mihály Vörösmarty, llegarian a posiciones extremas y revolucionarias como la de Attila József. La evidencia de que era una estructura superficial y aparentemente calma la que permitía el desarrollo de aquel amplio enclave centroeuropeo está en cómo desembocó, y con gran celeridad, en la disolución, después de la Primera Guerra Mundial. Lo que iba a quedar de aquel glorioso Imperio, con su artificiosa unidad, se diluyó en la unificación con Alemania y su gran derrota conjunta.

Los grandes intelectuales austríacos apoyaron decididamente, en su gran mayoría, la entrada en la Primera Guerra Mundial, del lado de Alemania, como si fuese algo justo, oportuno y adecuado, amén de glorioso. El resultado, per- dida la contienda, fue la desmembración radical de algo que antes muchos creian perfectamente unificado. La violencia institucional contra otras naciones era lógica desde el punto de vista de un Imperio que se concebía a sí mismo casi como perfecto, creciente y estable, al margen de los problemas que el pueblo llano podía padecer o no. Los intelectuales, en su conjunto, no alentaron entonces a la paz, sino que promovieron la defensa de los valores imperiales y tradicionales. Sin embargo, esa Viena en descomposición espiritual -asunto que no vio o no quiso ver Zweig- vivió culturalmente, hasta la victoria del nazismo, uno de sus períodos más ricos desde el punto de vista cultural, aunque con tendencias contrarias: la herencia de Wagner, continuada por Bruckner, Ricardo Strauss o Mahler, por un lado, frente al tradicionalismo de Brahms, se convertiría luego en la pugna con las vanguardias que surgieron tomando el nombre de la capital: la Escuela de Viena (Schönberg, Alban Berg y Webern), en una comunidad de sensibilidad similar a la que llevaría a Béla Bartók a desarrollar sus sonoridades o a Stravinsky en otros ámbitos. La tendencia dodecafónica o atonal de los emergentes compositores vieneses poco tenía que ver con el gusto burgués, era revolucionaria estética y casi políticamente, resultaba estridente y retomaba la tradición de lo sublime concentrada en sus elementos de ruptura y tragedia. En el lado opuesto, la belleza a menudo superflua de los diversos Strauss, de los valses, despreocupada, coqueta y suave. Junto a la Secesión Vienesa, encarnada en la arquitectura modernista de un Otto Wagner o en la pintura límite de Gustav Klimt, el otro extremo abrupto, obsceno y trágico, tensando la interpretación de lo sublime romántico en lo corporal, de Egon Schiele, o la vía germánica del expresionismo alemán: Die Brücke (siguiendo la estela de Munch: Nolde, Kirchner), a la que serían arrastrados austríacos como Kokoschka. Un arte roto para unos tiempos rotos, como el famoso grito de Munch. Frente a la reprimida moral burguesa de la época se establecian las teorías desarrolladas en los escritos de Freud. Frente a un Zweig liberal e ilustrado, aunque con restos románticos, se levantaban autores diversos, como el escabroso Kafka, el confuso Musil, el destrozado Paul Celan, no muy lejos, A. Schnitzler o H. Hoffmansthal, o en Alemania el también liberal Tomás Mann, el todavía joven Brecht y el bélico y titánico Jünger. Ese mundo cultural propio del entorno germánico, y en especial en Viena, produciria también en filosofía autores destacados, algunos bajo el afamado grupo del Círculo de Viena, desarrollando el neopositivismo (Otto Neurath, Frank, Morris 
Schlick, Rudolf Carnap) en consonancia con la elaborada por el Círculo de Berlín (Reichenbach, Hempel...) o tan peculiares como Wittgenstein. Sin embargo, el desarrollo del pensamiento filosófico y su variedad no pueden deslindarse de la influencia de autores alemanes tan variados como son: Nietzsche, Husserl, Hartmann, Max Scheller, los neokantianos (Cassirer, Windelband, Rickert) o Heidegger. Todo ello en una misma zona cultural. $\mathrm{Ni}$ sólo habitaba una unidad filosófica ni estética, ni una calma ordenada y armónica, sino que las graves y profundas contradicciones, los desajustes evidentes entre unos y otros, conducian a mundos que, rozándose en el mismo territorio fisico, sin embargo eran excluyentes, ciegos unos para otros o bien antagónicos.

Zweig vive, como burgués medio, cómodamente aposentado y amparado, adulado, por un notorio y firme éxito literario. En realidad, habita una torre de marfil y queda ajeno a los problemas de las barriadas obreras, recluido como un monje en su biblioteca suntuosa y llena de reliquias de sus venerados "santones" culturales: la pluma con la que escribía Goethe, el mobiliario de Beethoven... En un ejercicio casi religioso del placer que la cultura otorga con sus excelencias, como un ejercicio de yoga, relajación, o como una droga que hace evadirse, disfrutar y descansar, redacta biografías sobre los personajes que más estimulan su mitología personal, a la manera de un "teólogo de lo cultural": Fouché como paradigma del genio político en su versión tenebrosa, María Antonieta, o la belleza quebrada, como lo sería luego su Viena, Hölderlin, Kleist, Nietzsche, Tolstoi, Erasmo de Rotterdam, Dickens, Balzac, Stendhal, Casanova, Dostoievski, etc.

Incluso en su perspectiva política, liberal y conciliadora, se muestra esa tendencia a lo equilibrado, a lo claro y distinto, al punto medio, ajena a lo convulso y revolucionario; esto se trasluce también, como un carácter, en su obra literaria, como adoptando su modo de ser unas categorias estéticas que le resultan cómodas, más bien tendente a la representación de lo bello, $y$, aunque el tema sea dramático y trágico, la estructura de la obra, el modo de expresarse y la concepción de la totalidad no deja de ser equilibrada, comprensiva, apaciguada, como desde una razón que vertebrara el caos de pasiones y elementos irracionales. Esto no excluye, sin embargo, su parte entregada al sentimiento e incluso a cierta tragedia que viene a reforzar la tendencia hedonista y a la vez estoica de Zweig, como la que se trasluce claramente en su narrativa, La piedad peligrosa, o El jugador de ajedrez, por ejemplo; o en sus biografías (Fouché, encarnación del mal, pero excelencia del calculador; María Antonieta o la destrucción de una persona encantadora, belleza truncada por la barbarie; no trata apenas la miseria que el pueblo francés sufría mientras la linda reina derrochaba el dinero en fiestas superficiales y juegos ridículos, considerándola casi una mártir). Zweig es un ilustrado al estilo de Goethe, aunque menos profundo, menos metafísico, pero precisamente en una época donde la razón o la lógica ilustrada se descoyunta ante el surgimiento de la masa, controlada o incontrolada. El proletariado, miserable, descubre que hay un sistema que con supuestas razones explota o roba legalmente a los trabajadores, abusa de los demás con un supuesto orden ancestral que se perpetúa en estructuras cada vez más caducas, como la del Imperio. El orden social ha de tener también una cierta base racional o científica, no sólo sentimental e irracional; tal es la mentalidad emergente. Zweig no entiende lo que sucede cuando Marx, Engels, Bakunin o Kropotkin irrumpen en las mentes de muchos como una solución: la demolición del sistema por la violencia pues ese mismo sistema no deja otra opción para salir de la miseria. Para Zweig el proletariado parece una imagen de lo bestial en sí, lo burdo, lo ajeno a lo bello; tolerable si es conducido por la elite, al modo del propuesto en el Despotismo llustrado, aunque en su época fuera un despotismo compartido también por la burguesía, pese a la tendencia generalista de lo democrático. De esta manera de ser y concebir el mundo se comprende cómo corrientes que le son contemporáneas, pero demoledoras, como el dadaísmo y luego el surrealismo, le resulten ajenas, absurdas, locas, pues se nutren eminentemente de la estética del romanticismo más radical: lo sublime.

El comienzo de la segunda elegía a Duino, de Rilke, Jeder Engel ist schrecklich (Todo ángel es terrible), parece ajeno a la sensibilidad de Zweig, como si resultase intolerable una belleza que no pueda ser siempre, de alguna manera, confortable y equilibrada; una belleza convulsa y lo terrible de lo enormemente bello le hace huir como a Jonás le espantó la llamada de Jehová, cayendo en el vientre de la ballena, en medio de la tempestad que el racionalismo ilustrado llevó al casi puro irracionalismo de la Segunda Guerra Mundial. De hecho, ese horror a la locura se ve patente en sus trabajos y estudios sobre autores que su- 
ponen de algún modo la destrucción, tal es La lucha contra el demonio; locos o suicidas, como su mundo (es llamativo que Zweig acabara, desde su equilibrio, pero ante un mundo desequilibrado, suicidándose). En Francia florecian escritores como Leon Bloy, Huysmanns o d'Aurevilly y, más tarde, Cèline o Gracq, en un sentarse sobre las fisuras con las que aquel mundo parecía reventar, asentados en lo sublime pero sobre el vacío, perdida la totalidad y sin añorarla -hasta los autores católicos hablaban desde la parcialidad de una visión religiosa radicalizada-, contra la lógica ilustrada hacia la que luego vendrian a arremeter Beckett, Camus o lonesco, como después han mostrado algunos pensadores postmodernos.

El desarrollo de la civilización occidental en un grupo de potencias europeas divididas y con intereses comerciales contrapuestos, fue entendido por muchos como una confirmación del progreso ilustrado (evidente en el terreno científico, en las tecnologías y en la industria; en el poderío militar o económico de las naciones y en las libertades conseguidas por la población respecto a épocas pasadas) se vio truncado con la Primera Guerra Mundial. A partir de esta destrucción masiva que afectó a una buena parte del planeta, en muchas conciencias surgió como algo patente la idea de que el progreso no era algo firme ni un ascenso asegurado por la historia, que se podía retroceder, y que la racionalidad ilustrada se desmoronaba ante la irracionalidad de las instituciones más eminentes y preclaras que habian conducido a sus pueblos a una hecatombe. Para muchos intelectuales, la constatación de que los países "más civilizados" e ilustrados del planeta, con el pensamiento liberal asumido en gran parte, se destrozaban irracionalmente entre sí, no podía conducir sino a una sospecha sobre la misma racionalidad y sobre el liberalismo superficial entonces imperante; la lógica ilustrada -podían deducir algunosconduce a la guerra por causa de unos valores impuestos desde un estado presuntamente racional, aconsejado con científicos. Muchos de los intelectuales de ambos bandos, antes del conflicto, habían alertado y animado a la población a luchar por la patria contra el enemigo. Los que parecian más ilustrados habian sido instrumentos de la más trágica barbarie, desde una supuesta lógica y civilizada posición prestigiosa a la hora de señalar o emitir principios. El dadaísmo partía así de la razón como un fenómeno imposible; la demostración: el experimento de la misma historia.
De otro lado, después de la guerra, los barrios proletarios y humildes, los que casi no parecía visitar ni conocer Zweig, se llenaron de miseria con el periodo de crisis surgido del crack del 29 y fueron arrastrados como muchos otros lugares del planeta por la Gran Depresión, que produjo masivamente una intensa fabricación de parados y hambre. El liberalismo imperante en los restos del Imperio Austro-húngaro y en Alemania no supo atender a las necesidades de estas grandes masas menesterosas, para las que el estado de derecho poco importaba en lo que a sus vidas cotidianas respecta, para quienes apenas existía justicia o ley, ni había un verdadero consenso ni podía haber pacto social, pues para ellos las leyes favorecian fundamentalmente a las grandes fortunas y desatendian sus reclamaciones. Quien padece hambre poco puede decidir si no es salir antes de la extrema necesidad. ¿Para qué seguir unas reglas de juego impuestas por otros y que además perjudican a la mayoria? De ahí que las opciones radicales y extremas: fascismos y revolucionarios anarquistas o comunistas ganaran tantos adeptos y llegasen al poder amparados por unas mayorías para las que el sistema antes vigente había quedado a un lado.

La historia parece repetirse también en nuestros días, con el resurgimiento de los partidos de extrema derecha que se apoyan sobre todo en sectores amplios de una población que no se siente representada por los partidos tradicionales, tal ha sido el caso francés con Le Pen, el austríaco, con Haider $y$, en otra medida, lo que sucede en Holanda, Bélgica o Italia, en especial, ante el fenómeno de una inmigración cuantiosa y descontrolada, una de cuyas consecuencias ha sido el aumento de la violencia.

Desde el punto de vista económico, la solución para evitar conflictos revolucionarios fue aburguesar al obrero y convertirle en propietario. Aunque mayo del 68 se levantó frente a un sistema ético y en contra de unas costumbres que impedian más libertad en los muchos campos de la vida cotidiana: vestido, sexualidad, arte, etc. En cierto modo fue una revolución contra el aburrimiento que pretendía ser el único modelo de la sensatez. Lo irracional irrumpió también en su faceta alegre y positiva, en los bailes y en el amor. La lectura que Lukács, en Asalto a la razón, hace del irracionalismo teórico como fuente de los fascismos y de la Segunda Guerra Mundial, puede invertirse. Siguiendo los análisis de Glucksmann desarrollados en El undécimo mandamiento, las utopias ilustradas, tanto 
las de la Revolución Francesa como las de estilo socialista o marxista, al igual que las fascistas, han desembocado en atroces carnicerías, precisamente buscando un ideal supuestamente mejor para la humanidad. Ni todo irracionalismo es, de suyo, negativo y va necesariamente unido al fascismo, ni todo racionalismo o todo pensamiento ilustrado conduce necesariamente a lo mejor. Tal vez, como en el pensamiento individual que los seres humanos ejercitamos, sea precisa una sintesis de ambos, combinar razón, sentimientos, sentidos e intuición, también a la hora de analizar los fenómenos políticos, especialmente en la filosofía política, pues analizar los hechos políticos como si sólo fueran producto de la economía (Marx y algunas versiones del capitalismo extremo), o como si sólo fuera producto de una intrínseca racionalidad (Ilustración en su versión más típica y sobre todo Hegel), puede hacer retorcer el fenómeno para, torturado, hacerle decir lo que uno quiere escuchar de él, sin lograr ver lo que hay sino sólo lo que se quiere encontrar (es decir, lo que se puso inicialmente para analizar la cosa; las categorías y los prejuicios con los que se acudió a teñir y encasillar el fenómeno).

La perspicaz y sutil mirada de S. Zweig sobre no pocos autores a los que magistralmente biografió reposa en su atención analítica dedicada a los fenómenos de la mente, como se ve en La curación por el espiritu, en consonancia con las pautas establecidas por Freud. Sin embargo, se torna inexplicablemente opaca en algunos casos al analizar su presente o los posibles futuros; sólo cuando ya ha pasado, como en El mundo de ayer. Memorias de un europeo, vuelve a encontrar algunas de las ocultas claves con las que la historia se da a sí misma explicaciones. Buscar un argumento que aclare esta divergencia no es fácil, de no ser que algo tuviera que ver en ello su condición de judío, por un lado económicamente privilegiado, de otro algo apartado y excluido de cierta sociedad. Los escritos que otros autores más o menos contemporáneos del mundo germánico, como Bruno Bauer o el también de origen judío Karl Marx, sobre la cuestión judía, pueden resultar esclarecedores: según ambos, las comunidades judias tendian a concebir un estado no sólo al margen de los demás sino aun por encima de las demás sociedades, por cuanto era un pueblo elegido por Dios, y la ley de Dios estaría por encima de las demás. El fundamento se hallaba en una supralógica teológica capaz de invalidar las leyes humanas.
Lo religioso parece dejado de lado por Zweig, hasta el punto de que el protagonista de El jugador de ajedrez, un hombre encerrado en una habitación en perpetuo silencio, durante meses, sólo sacado de vez en cuando para los interrogatorios de los nazis, es capaz de aprender de memoria jugadas de ajedrez y aun un libro entero y hasta jugar contra sí mismo antes que hacer consideración alguna sobre la vida y la muerte, sobre si hay espíritu que viva más allá o lo religioso pueda tener o no fundamento. Pese a todo, las consideraciones que sobre la cuestión judía eran habituales, aunque individualmente puedan no afectar al mismo Zweig, por su distancia con la religiosidad judaica o su concepción personal del mundo, sirven de muestra para el grupo étnico y cultural en el que por nacimiento se vio inmerso. De hecho, cabria aplicarse en él, y a su rápido y fácil éxito en la vida económica y literaria, el famoso pensamiento de Feuerbach, según el cual uno es lo que come, si rico y feliz con el mundo, tendrá que ser conservador; si pobre y desgraciado, con tendencia a revolucionario. Ese vivir como en una burbuja social y cultural parece que le impidió ver lo que se le venía encima a su querida Austria Imperial, la Felix Austria, como si se concentrase en los objetos agradables que caían a sus ojos, en los paisajes humanos que le resultaban interesantes, cual si tuviera anteojeras, como un caballo que sólo quiere un recorrido, eso sí, a galope, de praderas florecidas. Por un lado extremadamente fino y sutil para los análisis psicológicos y culturales, como su correligionario y contemporáneo Sigmund Freud, y por otro tan superficial e incluso ciego para ciertas manifestaciones de lo político, lo social, lo metafísico y lo religioso. No es así extraño que se dedicase exclusivamente a lo más elevado del espíritu humano de lo que en la sociedad cultural hallara, o así lo pretendía, en un mundo de elites que compartía unos valores y unas sensibilidades muy poco desarrolladas en la gran mayoría de sus compatriotas. Así, sus Momentos estelares de la humanidad resultan además de un ejemplo de la grandeza de sus ansias y deseos, de su ideal, un posible refugio en la utopía, en el mundo de los héroes y de los dioses; una huida del mundo real que vivía la mayoría. Como si viviese en una escena teatral, entre héroes de cartón piedra, ajeno a la miseria real sobre la que se sustentaba, sin ver las maderas podridas con las que el tablado que hacía de escenario se levantaba con esplendores vacuos. Tal vez sin el contraste, sin la justa apreciación del mal y del horror, sin sentirlo y saborearlo, no sea posible una concepción honda y perdurable del bien o de la belleza, pues no sería propia del mundo que habitamos, entre los 
seres finitos y por tanto abocados al choque propio de los límites. La sintesis es necesaria, sin omitir completamente a ninguno de los contrarios. La finitud implica negación, no ser; y de fomentar lo negativo, no se puede mirar como si no existiese la falta de ser, los límites o las negaciones, como si la nada tuviese un modo específico de hacerse notar, siendo, de algún modo, relacional, absurda en su ser que no es, pero se hace notar. Zweig, incluso en sus novelas y relatos más trágicos, tiende a hacer una flor delicada. Rehuye el horror y el dolor puro y lo suaviza con sedas de románticos sentimientos.

El punto medio del liberalismo conservador al que Zweig tendía tal vez se vea bonito cuando a uno, como él, le van bien las cosas, imbuido en una rica y fecunda vida burguesa, enriquecida por la economía y el arte, aunque evasiva ante ciertos problemas. Sin embargo, la legitimación de ese sistema se derrumbó ante el común de las gentes cuando estallaron los graves problemas sociales derivados del desastre de la Primera Gran Guerra, especialmente destructiva y absurda, tras aniquilar a millones de seres humanos, ciudades y pueblos, y todo a veces por unos metros de trinchera ganados o perdidos con esfuerzo de miles de muertos, una guerra que cercenó la vida de todos, dejando una generación perdida, heridos y mutilados, junto a muertos, en prácticamente todas las familias. Iglesias y palacios, multitud de obras de arte, fueron arrasadas, junto a las vidas de los hombres, entre los paises supuestamente más civilizados, desarrollados y con una cultura que se consideraba superior a las demás. Valle Inclán relata con detalle sus vivencias en el frente francés: "Al estampido de las bombas surgen las Ilamas de los incendios: Arden las mieses, y las sobrecogidas aldeas, y las ciudades que lloran derrumbarse las torres de sus catedrales" (Valle Inclán, 1995, 175). El bombardeo de Reims y su fabuloso templo gótico, uno de los más emblemáticos de Europa, por parte de las tropas alemanas a las que Valle tilda de bárbaras e incivilizadas, sin pasado ni cultura, todavía sujetos al yugo de un emperador y por tanto primitivas, tiene aspectos patéticos que recuerdan a la descripción del final de Sobre los acantilados de mármol de Jünger, escrito años más tarde por uno que participó activamente junto al ejército que provocaba tales destrucciones: "Las bombas caen sobre la catedral, el barrio que se tiende a su espalda yace todo en ruinas, y es un montón de piedras mutiladas aquella capilla donde eran consagrados los reyes de Francia. En el viejo atrio desierto, el rumor de la guerra adquiere un sentido de vida sacrilego y bárbaro"(Valle Inclán, 1995, 232). En realidad, por desgracia, nada nuevo. Goethe, tan querido de Zweig, relata sin asombrarse de ello, lacónicamente, como algo normal, la destrucción de la catedral de Maguncia que él mismo pudo ver directamente mientras se producía, junto a las tropas prusianas y monárquicas y contra una ciudad alemana que intentaban rescatar del dominio de los republicanos franceses y su bandera de libertades: "28 de junio, de noche. Bombardeo prolongado contra la catedral; torre y techumbre arden, y muchas casas alrededor; después de medianoche, la iglesia de los jesuitas" (Goethe, 1932, 355). Junto con la creencia en una cultura superior, después de la Primera Guerra Mundial se desmoronaron, entre las ruinas de las ciudades y pueblos, junto a las ruinas humanas, algunos cetros considerados casi como eternos, el emperador alemán Guillermo II huye y comienza la república, el Imperio Austro-húngaro se disuelve y la antes altiva Viena se reduce a capital de una pequeña región que deviene república con pretensiones, y los zares desaparecieron bajo la revolución soviética. La plácida tranquilidad de un Imperio esplendoroso cede paso a la miseria: "En el imperio Austro-Húngaro la situación alimenticia es todavía mucho más grave. Aunque Hungria apenas se ve afectada, las regiones montañosas e industriales de Austria son víctimas del hambre, y se imponen al ejército los fleischlose Tage, los días sin carne; el racionamiento insuficiente y la pésima situación sanitaria desmoralizan tanto al ejército como a la población" (Crouzet, 1982, 35). Alrededor de diez millones de cadáveres, varios millones más de heridos y mutilados, y una devastación material que resultaba impensable pocos años antes. La concepción mítica del combatiente como un caballero se derrumba ante la amargura y la decepción que proporciona a las tropas una guerra mecánica donde la masa humana sólo sirve de carnaza en grandes cantidades para no lograr apenas conquistar nada.

El orden legitimado por tronos y leyes, por tradiciones y bendecido por el clero de cada lugar se derrumba estrepitosamente dejando un vacío rápidamente ocupado por los que proponen soluciones radicales, como radical fue la autodestrucción de ese orden de estilo decimonónico: comunistas y fascistas proponen demoler de modos diferentes los restos del sistema para poder construir encima sus quiméricas soluciones. La vida cómoda de los ciudadanos de la capital del Imperio Austro-Húngaro se ha de ajustar a la rotunda derrota, a la demolición de los viejos valores y una realidad política mínima respecto a lo que 
antes habían sido. Los fatuos esplendores y los honorables valores en los que parecian sostenerse poco antes tan firmemente ya apenas tienen sentido después de la hecatombe producida por la corte que, como un adorno, escuchaba sinfonías de Mozart o bailaba los valses de los Strauss. La miseria general de la población y la falta de trabajo para aquel mundo de porcelana y cristal de Bohemia que antes se sentía en lo más alto le daba un aspecto resquebrajado y polvoriento, logrando, ante las necesidades acuciantes de una espantosa posguerra del derrotado, que el liberalismo resultara entonces una propuesta gris y casi estéril. Comunistas y luego nazis, con otros grupos radicales, prometían en cambio soluciones drásticas para problemas dramáticos, respuestas tajantes a preguntas acuciantes. Sin un fuerte ímpetu interior (movido por la religión o por una sublimación religiosa del arte o de la política, allí donde pueda sentirse o imaginarse, vislumbrarse o palpar la sublimidad, la infinitud) el liberalismo de Zweig frente a los problemas de masas, en especial frente al mundo obrero, resultaba, además de caduco, estéril, mediocre y "burgués" en el sentido más peyorativo que la palabra tiene entre el léxico revolucionario y en especial en el marxismo.

Zweig, por otro lado, creía en la fuerza de los intelectuales para influir en la sociedad, en su capacidad de acción sobre el entorno político, como un grupo sacerdotal, una elite escuchada y directora de los destinos del mundo. Esta concepción se mantenía en pie ante sus ojos, hasta que el nazismo le expulsó de su torre de marfil, de su querida concepción del mundo y de la cultura, por otro lado, originariamente romántica, de raíz ilustrada y oriunda de la República Platónica. Lo que no veía o no quería ver es que, en el período de entreguerras, buena parte de los intelectuales se entregaron a los movimientos de masas, a las soluciones radicales, reclamando soluciones con urgencia. La necesidad extrema de los que pasaban hambre, los que habian perdido al cabeza de familia en la guerra, los mutilados y todos los que habían visto desvanecida la frágil tranquilidad del pasado, en el caso de los que la tuvieron realmente, unido a los que no veían abierto futuro alguno, convertía el sistema liberal en un entramado de lujo, sólo interesante para unos pocos privilegiados que veían real la aportación de sus decisiones voluntarias. La gran mayoría quedaba aparte, ajena a unas libertades civiles (prensa, elecciones...) que no resultaban prácticas para sus intereses vitales, pues poco o nada de lo que en el estado podían elegir les resultaba útil o satisfactorio y por lo tanto el sistema general donde se mueven las alturas políticas e informativas les parecía realmente algo ajeno; lo cercano, una burocracia ineficaz, siempre kafkiana pese a la desaparición del Imperio, ineficaz para resolver sus verdaderas necesidades. Para las masas menesterosas se hacía preferible una dictadura que les librase de la miseria, que les liberase del hambre (la primera de las esclavitudes), a unas libertades generales en las que poco o nada podian decidir; antes que seres humanos (libres) somos animales y las necesidades elementales (cobijo, nutrición, seguridad...) difícilmente se anulan, cuando no se solventan, con una situación más o menos estable en lo general pero que en poco puede resultar convincente para el particular que piensa en particular y sufre su particularidad.

Parte de las elites culturales se arrojó en brazos de las "soluciones" extremas, únicas posibilidades novedosas y esperanzadoras ante un mundo ya caduco, "el mundo de ayer", a veces convencida, otras como quien apuesta por un cambio, el que sea, ante una situación insostenible. Acusar a la minoría judía que tenía relevancia económica resultaba fácil. Sin embargo, otros, entre los intelectuales, decidieron huir, como los filósofos componentes de la Escuela de Frankfurt, músicos como Schönberg, pensadores o científicos como Freud y Einstein, escritores como Tomás Mann, Hermann Hesse o el mismo Zweig. Entre los que quedaron, algunos ligados al comunismo se fueron radicalizando hasta desaparecer o pasar a la acción (las diversas "resistencias"), pronto aplastados; otros, como Jünger, D'Annunzio en Italia o Céline en Francia, se vieron ligados de una u otra manera a la marea ascendente de las diferentes formas con las que brotaba el fascismo. Zweig se estrelló contra el duro suelo de la realidad al caer de su nube, con la decepción del intelectual de prestigio y éxito reconocido que confiaba en su influencia en la sociedad que años antes le alababa (como los filósofos y escritores antes de la Revolución Francesa: Voltaire, Rousseau, Diderot, D'Alambert, etc.), al estilo ilustrado. El desmoronamiento de una sociedad y unos valores en los que creía como firmes y estables se le hizo tan horrendo como increíble, y es que, como buena parte de la intelectualidad de nuestros días (ante los problemas de la inmigración, el envejecimiento de la población, la nueva situación mundial y la emergencia y triunfo de partidos de extrema derecha...) vivía fuera del mundo real, ajeno a lo que era, realmente, la situación de la mayor parte de la población; por vivir en una nube, en los sueños de un arte que vino a ser de evasión, como un don Quijote imaginado, sin acción, y desterrado. 


\section{BIBLIOGRAFÍA CITADA}

Crouzet, Maurice (1982): La época contemporánea, Barcelona, Destino.

Recibido: 22 de diciembre de 2009 Aceptado: 23 de enero de 2010
Goethe, Johann Wolfgang (1932): Sämtliche Werke, Berlin, Im Propeläen-Verlag (edición general de su obra completa en München, Müller Verlag), Hrsgben. Kurt Noch, vol. 34.

Valle Inclán, Ramón María del (1995): La media noche, Madrid, Espasa-Calpe, Austral. 